\title{
Anterior Myocardial Infarction and Nitinol Mesh Occluder for Atrial Septal Defect, a Fortunate Discovery
}

\author{
MARIA-CRISTINA VLADEANU ${ }^{1}$, IRIS BARARU BOJ AN ${ }^{1 *}$, TEODOR VASILCU², ANDREI BOJ AN ${ }^{3}$, DAN ILIESCU², \\ PAUL-DAN SIRBU4*, IGOR NEDELCIUC ${ }^{5}$, MANUELA CIOCOIU*, CODRUTA BADESCU², MAGDA BADESCU1, \\ CARMEN ELENA PLESOIANU ${ }^{2}$, OANA-VIOLA BADULESCU ${ }^{1}$ \\ ${ }^{1}$ Grigore T. Popa University of Medicine and Pharmacy, Department of Pathophysiology, 16 Universitatii Str., 700115, Iasi, Romania \\ ${ }^{2}$ Grigore T. Popa University of Medicine and Pharmacy, Department of Medical Sciences, 16 Universitatii Str.,700115, Iasi, Romania \\ ${ }^{3}$ Grigore T. Popa University of Medicine and Pharmacy, Department of Surgical Sciences, 16 Universitatii Str.,700115, Iasi, \\ Romania \\ ${ }^{4}$ Grigore T. Popa University of Medicine and Pharmacy, Department of Orthopedics and Traumatology, 16 Universitatii Str.,700115, \\ lasi, Romania \\ ${ }^{5}$ Arcadia Hospital, Interventional Cardiology Department, 38 Sararie Str., 700116, Iasi, Romania
}

\begin{abstract}
Atrial septal defects represent an abnormal communication between the left and the right atria. Some patients may experience dyspnoea, fatigue, others may suffer directly from complications, like arrhythimias, paradoxal embolisation, resulting in stroke, but some remain asymptomatic until adulthood. When possible, the gold standard treatment is percutaneous closure with nitinol messh occluder. We are presenting the case of a 50-year-old patient with an acute anterior myocardial infarction, whose echocardiography showed akinesia of the left ventricular apex and anterior wall, as well as a surprise element, not connected to the myocardial infarction, a $22 \mathrm{~mm}$ atrial defect, with a shunt ratio higher than 1.5. Our first concern was the cardiovascular emergency. The coronarography revealed a critical stenosis of the proximal left anterior descendent and we introduced a stent. In a second phase, we evaluated the atrial septal defect. Since ithad indication for percutaneous closure, we decided to use an Amplatzer occluder. The intervention was a success, with no residual shunt. The patient's follow up was good, with no cardiovascular events. Most of time, cardiovascular diseases are not isolated, but come together, related or not to one another. An adequate management implies treating the cardiovascular emergency first and solving the associated lesions in a second phase.
\end{abstract}

Keywords: atrial septal defect, anterior miocardial infarction, amplatzer occluder, transcatheter closure

Cardiovascular diseases are often associated with or without a connection between the pathologies. It is not very rare for patients to present in the emergency department with an acute pathology and to discover other associated comorbidities while the main disorder is being investigated. Such is the case of our 50-year-old patient who was admitted and treated for myocardial infarction, but in the process we also discovered an atrial septal defect type ostium secundum.

Acute coronary syndromes represent a common, widely spread pathology, with a high rate of complications and commorbidities around the world [1] and account for almost $30 \%$ of the annually death causes on the Globe [2]. Presentation forms of this syndrome can either be unstable angina, or acute myocardial infarction (with or withoutSTsegment elevation) [3,4]. Cardiology guidelines establish that the optimal treatment consists of myocardial revascularisation (percutaneous or through by-pass, depending on the severity and location of the vessel lesions) [5].

Atrial septal defects are congenital malformations responsible for an abnormal communication between the right and the left atria. The most common form is the ostium secundum type (75\% of all cases), located by the fossa ovalis [6]. There can be a great variability of the clinical panel, from asymptomatic to highly symptomatic cases, mainly depending on the size of the defect. It is generally believed that defects smaller than $5 \mathrm{~mm}$ are mostly asymptomatic, a size between 5 and $10 \mathrm{~mm}$ causes symptoms in the forth or the fifth decade and and the defects which are larger than $10 \mathrm{~mm}$ are associated with symptoms in the third decade [7]. The most important diagnostic tool is echocardioghraphy, especially transoesophageal echocardiography (TEE), which establishes the localization and the size, the presence of the shunt, the pulmonary to systemic flow ratio, the consequences on the right heart, as well as the indication of percutaneous or surgical closure $[1,8]$.

\section{Experimental part}

A 54-year old patient was transferred to our Cardiology Unit from a territorial hospital, after being diagnosed with anterior acute myocardial infarction. On admission, the patient was stable, with a blood pressure of $140 / 80 \mathrm{mmHg}$. He had several cardiovascular risk factors (dyslipidemia, obesity, smoking), but he had no history of a previous cardiovascular events. The electrocardiogram was positive for anterior acute myocardial infarction, with ST segment elevation in the anterior leads. As expected, the echocardiography revealed apical and anterior wall of the left ventricle akinesia, with a reduced ejection fraction of $40 \%$. But there was also a surprise element: an ostium secundum atrial defect, with a left to right shunt, which had not been diagnosed before, as this was the patient's first echocardiographical examination. Since the 
myocardial infarction was an emergency, we phocused on solving the acute coronary syndrome.

We performed a coronary angiography. The right coronary was normal, but when we cannulated the left artery, after injecting the contrast substance, we identified the occlusion of the left anterior descending artery (fig. 1). According to the indication of the European Society Guidelines, this case has a clear indication of percoutaneous coronary intervention. We introduced a drug eluting stent in the occluded artery. After balloon inflation of the stent, we obtained the reperfusion of the artery, with a TIMI 3 flow.

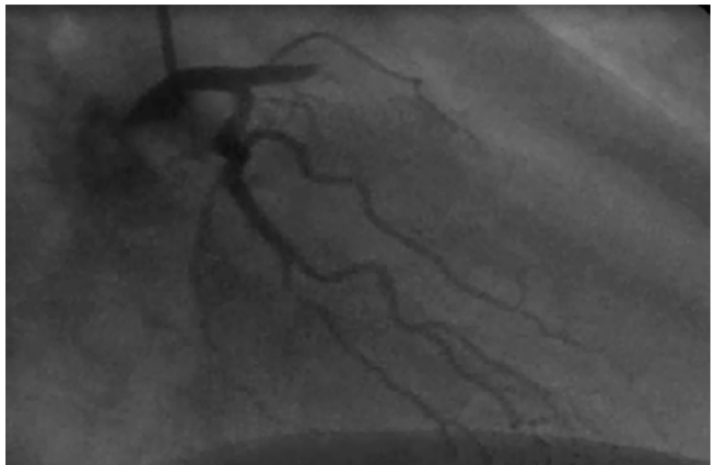

Fig. 1. Left anterior descending coronary artery with total occlusion

The next step was to analyze the atrial septal defect. Echocardiographical measurements identified a $22 \mathrm{~mm}$ defect, type ostium secundum, with left to right shunt, a pulmonary to systemic flow ratio of 1.7, a small degree of enlargement of the right cavities and a tricuspid valve gradient of $30 \mathrm{mmHg}$. Using TEE, we measured larger than $5 \mathrm{~mm}$ distances from the margins of the atrial septal defect to the coronary sinus, atrioventricular valves and right upper pulmonary veins. All those criteria sustained the decision of a percutaneous closure, using a nitinol Amplatzer prosthesis. The patient was scheduled for the next step, after the recovery period of the myocardial infarction.

\section{Results and discussions}

We used an Amplatzer device, which is formed of two self-expandable discs, connected by polytetrafluoroethylene (PTFE) and a nitinol mesh waist. The procedure was guided by fluoroscopy and the device was succesfully introduced and expanded, with no adverse events (fig. 2). The post-procedure TEE revealed a correctly inserted device, with no residual shunt.

Percutaneous closure is the preferred technique for the treatment of atrial septal defects, when possible, as it avoids opening the sternum, associated hemorrhage risk, cardiopulmonary by pass and cardioplegia [9]. Our patient had favorable criteria for this procedure.

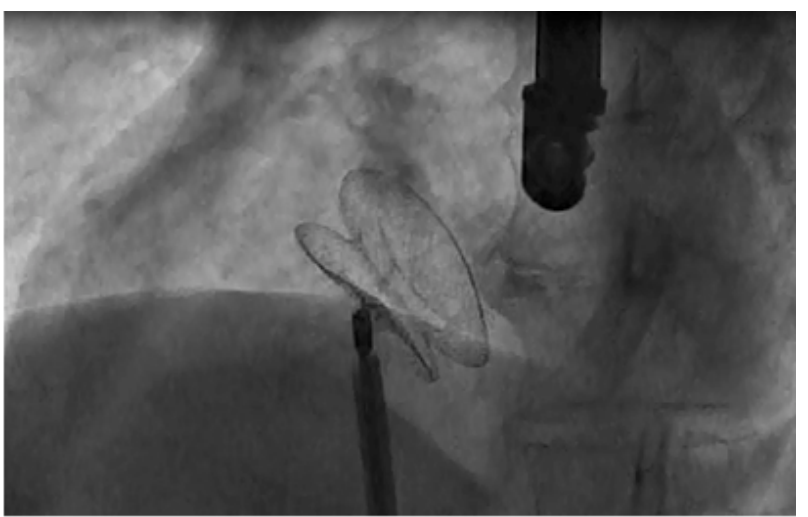

Fig. 2. Fluoroscopy image: expanded atrial septal defect closure device
The ASD occluder is a self-expanding double disc device, with a nitinol mesh waist in-between, which has the important characteristic of shape memory, allowing the device to gain the original shape after being advanced through a catheter. The nitinol mesah is actually the part that closes the defect. After the deployment, the adequate position is verified with the help of TEE. The technique itself is not very difficult and the succes rate is high, with a minimal complication rate [10].

What is particular about this case is the fortunate discovery of this congenital malformation at the age of 50 . The patient claimed to have been asymptomatic and had never done an echocardiography before. It is not very unusual for patients to have minimal symptoms, until the development of severe pulmonary hypertension and right heart enlargement and dysfunction, due to volume overload. Also, with time comes left ventricular stiffness, which agravates the left to right shunt. However, even though patients may remain asymptomatic until adulthood, complications may occur, for example arrhythmias and embolisations [11]. This emphasizes the importance of a complete cardiological investigation early in life, especially if one has cardiovascular risk factors.

\section{Conclusions}

Most of the time, cardiovascular diseases are not isolated, but come together, related or not to one another. An adequate management implies treating the cardiovascular emergency first and solving the associated lesions in a second phase.

\section{References}

1.RUFF C.T., BRAUNWALD E. The evolving epidemiology of acute coronary syndromes. Nature Reviews Cardiology 2011; 8: 140-147.

2.YUSUF S., REDDY S., OUNPUU S., ANAND S. Global burden of cardiovascular diseases: part I: general considerations, the epidemiologic transition, risk factors, and impact of urbanization. Circulation 2001; 104: 2746-2753.

3.FRIEDLANDER Y., SISCOVICK D.S., ARBOGAST P., et al. Sudden death and myocardial infarction in first degree relatives as predictors of primary cardiac arrest. Atherosclerosis 2002; 162: 211-216.

4.CHEN Y.H., LIU J.M., HSU R.J. Angiotensin converting enzyme DD genotype is associated with acute coronary syndrome severity and sudden cardiac death in Taiwan: a case-control emergency room study. BMC Cardiovascular Disorders 2012; 12: 6.

5.TUDORAN, M., TUDORAN, C., CIOCARLIE, T., Aspects of heart failure in patients with ischemic heart disease after percutaneous coronary revascularization with polymer-coated drg eluting stents versus baremetal stents., Mat. Plast., 56, no.1,2019, p.37-40.

6. WARNES CA, WILLIAMS RG, BASHORE TM, et al. ACC/AHA 2008 guidelines for the management of adults with congenital heart disease: a report of the American College of Cardiology/American Heart Association Task Force on Practice Guidelines (writing committee to develop guidelines on the management of adults with congenital heart disease). Developed in collaboration with the American Society of Echocardiography, Heart Rhythm Society, International Society for Adult Congenital Heart Disease, Society for Cardiovascular Angiography and Interventions, and Society of Thoracic Surgeons. J ornal of the American College of Cardiology 2008;52:e143263.

7.CRAIG RJ, SELZER A. Natural history and prognosis of atrial septal defect. Circulation. 1968;37:805-15.

8. BAUMGARTNER H, BONHOEFFER P, DE GROOT NM, et al. Task Force on the Management of Grown-up Congenital Heart Disease of the European Society of Cardiology (ESC); Association for European Paediatric Cardiology (AEPC); ESC Committee for Practice Guidelines (CPG). ESC guidelines for the management of grown-up congenital heart disease (new version 2010) European Heart J ournal. 2010;31:2915-57. 
9. MARTIN S., SHAPIRO E., MUKHERJ EE M. Atrial septal defects-clinical manifestations, echo assessment, amd intervention. Clinical Medicine Insights: Cardiology 2014; 8(s1):93-98.

10. SPIES C, TIMMERMANNSI, SCHARADE R. Transcatheter closure of secundum atrial septal defect in adult with Amplatzer septal occluder.
Intermediate and long-term results. Clin Res Cardiol. 2007;96(6):3406

11. WEBB G, GATZOULIS MA. Atrial septal defects in the adult: recent progress and overview. Circulation. 2006;114:1645-53.

$\overline{\text { Manuscript received } 11.01 .2019}$ 